\title{
"Does a Glass of White Wine Taste Like a Glass of Domain Sigalas Santorini Asirtiko Athiri 2005?" A Biosemiotic Approach to Wine-Tasting
}

\author{
Jonathan Hope • Pierre-Louis Patoine
}

Received: 7 October 2008 / Accepted: 14 November 2008 /

Published online: 11 February 2009

(C) Springer Science + Business Media B.V. 2009

\begin{abstract}
The object of our paper is to examine how wine-related knowledge and practices play an important role in determining the respective flavour experiences of novice wine drinkers and sommeliers. We defend the idea that sensation is informed by knowledge, as it circulates in a cultural environment. Biosemiotics has developed appropriate concepts helping us understand how the same wine can generate diverging experiences. Within a biosemiotic framework, we consider wine flavours as relational, semiosic experiences produced by the convergence of sensorydiscriminative, motivational-affective and cognitive-evaluative factors. Drawing from fundamental biosemiotics we argue that these factors vary according to the creature and its simultaneously biological and cultural umwelt. We conclude by examining a series of empirical studies consolidating the idea that sensation is informed by knowledge and language.
\end{abstract}

Keywords Wine-tasting $\cdot$ Sensation $\cdot$ Bodymind $\cdot$ Biosemiotics $\cdot$ Neurology Knowledge

\section{Introduction}

You are on Syros Island discussing biosemiotics and sharing a bottle of Domain Sigalas Santorini Asirtiko Athiri 2005 with some friends. After a few sips, you all agree on the wine's refreshing and pleasant character. However, while one of you appreciates the lime notes in the wine you disagree, tasting rather the spiky green apple flavour, as indicated on the tasting note of the bottle. Drinking wine often leads to discussions of this sort, uncovering the blunt fact that our sensational experiences recurrently differ.

\footnotetext{
J. Hope $(\bowtie) \cdot$ P.-L. Patoine

Département d'études littéraires, Université du Québec à Montréal, CP 8888, succursale Centre-Ville, Montréal, QC H3C 3P8, Canada

e-mail: hope.jonathan@courrier.uqam.ca

P.-L. Patoine

e-mail: pl_patoine@yahoo.fr
} 
Commonality of sensation is a puzzling question that has interested philosophers and natural scientists for centuries. We would like to contribute to the exploration of such a question by reflecting on wine tasting or, more specifically, on wine flavours as complex gustatory, olfactive, tactile, but also semiotic experiences. Our paper proceeds from a simple query: how can we explain that a same glass of wine produces so many various reactions, especially if we compare those of a novice drinker and those of an expert sommelier? And how can this phenomenon be explained in semiotic terms? The hypothesis we will examine is the following: the development of wine-related knowledge and practices plays an important role in determining the respective flavour experiences of novice wine drinkers and sommeliers. Thus we will defend the idea that sensation is informed by knowledge, as it circulates in a cultural environment.

We chose sommeliers as a case study to explore our hypothesis, but cheese makers, beer brewers, perfumers or even musicians could have served the same purpose. Indeed, in each of these examples, there is an immediate relationship between the sensing biological body and the realm of knowledge, culture, representations, and language. It is the enthusiasm of researchers for wine-tasting that encouraged us to add our biosemiotic approach to their work in cognitive and neuropsychology, biochemistry, and linguistics.

We have noted that those disciplines often fail to apprehend wine-tasting in its simultaneously physiological, psychological and cultural complexity. In contrast, biosemiotics has developed appropriate concepts to help grasp the interaction between bodily and cognitive experiences, hence allowing us to offer a tentative answer as to how the same wine can generate so many diverging experiences. Within this biosemiotic framework, we will consider wine flavours as interpretative experiences that begin as protoconscious neurobiological processes informed by knowledge and language. Indeed, consciousness - and flavour is a dimension of consciousness - emerges from complex interactions between our neuroanatomical apparatus and various physical and cultural objects.

It is this biosemiotic process of consciousness modulation that we propose to examine here through five steps - keeping in mind that our objective is to understand the wine-tasting experience from a general semiotic, Peircean, perspective.

A review of previous efforts at conceptualising wine-tasting will first be necessary in order to show how semiotics can properly address wine-tasting and avoid certain conceptual pitfalls: namely the dualistic paradigm that compels us to think about taste as being either subjective or objective. We will then examine how a relational conception of taste, based on Peirce's semiotic principles and Jamie Goode's reflections on wine-tasting, offers a way out of the aforementioned paradigm. Thirdly, a comparative explanation of the related subject of pain perception will help us clearly show how flavours, like pain, are not independent qualities but multilayered relationships between the sensor and the sensed. In a fourth point, we will show how Uexküll's classical distinction between the umwelt and the surroundings can be used to conceptualise the interrelation between the taster's everyday environment and his tasting abilities. In a fifth and final section, we will discuss experimental studies revealing how high-order cognitive and linguistic processes can influence what is commonly understood as a basic sensational experience. 


\section{Some Attempts at Explaining the Wine-Tasting Experience}

Though various books focus on the subject of wine, not many actually conceptualise wine tasting. Two substantial academic books must be mentioned however; first is Questions of Taste. The Philosophy of Wine, edited by Barry Smith in 2007b; second is Wine and Philosophy. A Symposium on Drinking and Thinking, edited by Fritz Allhoff in 2008. Each book is a collection of varied wine-related articles which are, for the most part, and unfortunately, not very useful for semiotics. Indeed, most of the contributions, when they are of philosophical nature, debate on the subjective and objective aspects of wine tasting, missing out, we believe, on the actual wine tasting experience. Two authors in particular adopt philosophical stances that appear highly problematic.

In "Knowledge, wine, and taste: What good is knowledge (in enjoying wine)?" (2007) Kent Bach, professor of philosophy, defends the idea that tasting is a sensorial event that absolutely precedes its cognitive and linguistic treatment. Making some sort of anti-representationalist claim, according to which wine-tasting can be effectively carried out oblivious of a social and linguistic network, and without any cognitive evaluation, Bach writes:

"The question boils down to this: does the wine taste different now that its qualities are singled out and labelled, or does the description ring true because it captures the experience one was already having? I'm inclined to opt for the latter answer: the description rings true not because it reveals something new but because one's experience already fits in." (37).

Bach then adds: “(h)owever, I don't think there's any way to argue conclusively for this" (37), which is, to say the least, unconvincing. In "Talk about Wine" (2008) Bach pursues his idea claiming: "(b)eing able to verbally identify the qualities in a wine is not really needed to be able to sense, notice and recognize its qualities." (109). Seemingly unaware of contemporary findings in neuropsychology - a point to which we will return later-Bach opines that knowledge and language are not important in wine appreciation.

Adopting a similar anti-representationalist stance, Barry Smith, professor of philosophy of language and mind, considers tasting to be mainly an objective experience - objectivity being in this case defined as the result of consensus. In "The Objectivity of Tastes and Tasting" (2007a), Smith condemns the idea that wine appreciation is a private experience and states: "( $\mathrm{t}$ )astes are properties a wine has that give rise to certain experiences in us; and they cannot be reduced to, or equated with, those experiences." (62). He continues:

"Tastes are real properties of wines even though they bear an essential relation to the subjective experiences of creatures like us. We cannot think about or identify them save in terms of our subjective experiences, but they exist whether we experience them or not. They are there to experience. They are not in us, they are in the wine, while the pleasures they give rise to are in us not in the wine." (63).

Smith is adamant: "tastes are real, objective properties of wines" (68). It is precisely for this reason, he surmises, that people can discuss (agree or disagree) on 
the wine's qualities. Although the idea that wines, as chemical objects, have material, objective properties seems uncontroversial, Smith's much stronger claim that tastes exist as such, and do not depend on a taster precisely cued to respond to them in certain ways, is an idea incompatible with a biosemiotic framework and can be persuasively contested, as we shall soon illustrate.

\section{Towards a Relational Conception of Taste}

Amongst the various articles in Smith's and Allhoff's books, the reflections of one author shine out and take us to the heart of our subject. Indeed, Jamie Goode, distinguished wine critic, trained biochemist and contributor to both volumes, has a surprisingly semiotic argument. In his article "Wine and the Brain" (2007), Goode states:

"I'm going to argue (perhaps controversially) that the way rating or scoring wine is currently practised is based on a false premise: that when a critic rates a wine, they are assessing the wine, and that any score thus produced is a property of the wine. This is incorrect. We need to make the subtle yet important paradigm shift of seeing a critic's assessment as a rating of that critic's perception of the wine. To put it another way, the critic is actually describing a conscious representation of their interaction with the wine, and therefore the score or rating is a property of that interaction and not the wine itself." (80).

For us, Goode could not be more on track. In fact, in a semiotic context he need not mention that his position is controversial, on the contrary it is pretty much consensual. However, his mentioning that his proposition might be controversial just goes to show how ignored basic semiotic concepts still are. ${ }^{1}$ Semiotics in the Peircean tradition considers and explains phenomena in terms of relativity, that is to say: 1) they are the product of relationships, the result of a reciprocal relation between the sensor and the sensed; and 2) contingent, conditional and determined by

\footnotetext{
${ }^{1}$ In Smith's and Allhoff's books, the only critique of the idea that flavours might be relationships or interactions comes from Smith himself. In an end-note, Smith writes: "Even if we claim that tastes are interactions between the wine and the taster, the issue of how subjective or objective they are remains open." (2007a). However, is thinking of taste within such a dualistic paradigm an epistemologically solid starting point of inquiry? Cleary, Smith believes so and considers the case closed: "If our reactions to a given wine differs then tastes will be, to that extent, subjective; whereas if, as normal tasters, we respond in similar ways, under similar conditions, tastes will be objective, or at any rate, inter-subjective. Therefore, nothing about the current issue is settled by taking the interactionist view." (76). By writing this, Smith dismisses the explicative potential of the concept of taste as a result of complex biosemiotic relations and, instead, relies solely on a posteriori social consensus as criterion of taste. What is a "normal taster" and which processes lead to his reaction or response are also unclear. What is clear, however, is the problem with Smith's interpretation of wine-tasting when he states that the objective properties of wine "are known to us through the distinctive experiences the tastes of the wine give rise to in us." (60). This sentence presents in fact a double problem. Firstly, tastes do not give rise to experiences, tastes are experiences as such. And secondly, Smith explains taste as if things going on in the body eventually correspond to something going on in the mind, "in us"; but the body is us, not some separate entity. Smith's idealism prevents him, we believe, from grasping the fact that sensations make us up. Part of the problem with Smith's description of wine-tasting and evaluation rests on the manner in which he describes the interaction between the body and the mind.
} 
the constitution of these interacting bodies (constitution which is itself dependent on the physical and symbolic environment in which they have evolved). What this means is that a smell or a taste is the product of a relationship, the result of multilayered or parallel interpretive processes, and not an independent quality.

Interpretation is a relation-particular in that it deals with meaning - an evolving relation between an object, what it stands for, and for whom (or for what) this standing for occurs. We recognise in this formulation Peirce's classical semiotic triad, constituted within a logic of relatives uniting an object, a sign and an interpretant. In the case of wine tasting, the object is the bottle with a name, a history, a grape variety, along with a molecular organisation capable of producing reactions to the nose and palate; the sign is the assessed wine; and the interpretant is what the drinking induces (including the intoxication, of course), the sum of the actual sensations and ideas produced. As the tasting unfolds, those three poles are continually transformed, evolving with the interactive process of semiosis, of the sign's development.

A wine-related example will make this clear. The citrusy flavour (lime, lemongrass, grapefruit) and the crispiness or refreshing green apple acidity one might find in a Domain Sigalas Santorini Asirtiko Athiri 2005, are in fact the results of complex relations tying the wine to the taster. Recognising and feeling these qualities requires an interpretative relation; the wine-tasting experience is a signifying process. The citrusy and apple flavours are not in the wine as suchthey are not even in the "real world, physical" fruits - nor are they in the mind of the drinker. Rather, they are the way our chemoreceptors react to certain molecular organisations combined with the way language and cognition react, correspondingly, to those sensorial fluctuations in a specific context, by crystallizing, defining and modulating them into conscious forms.

Basic sensory information can be understood as an event: the actual reaction of a sensor specifically cued to respond to features of a certain set of objects. However, and as we have just argued, this basic sensory information is only part of the taste per se. In contrast to Smith's view of taste as giving rise to experiences in us, we argue that taste is the experience itself, and that the basic sensory information is only a pole, however crucial, of semiosis. That is why a sip of Sigalas Santorini can make someone taste lime while you taste apple.

\section{Pain Perception: A Comparative Explanation of Taste}

At this point, it can be enlightening to consider the similar case of pain perception as studied by Ronald Melzack and Joel Katz-a neuropsychologist and an anaesthesiologist respectively.

Up until the second half of the 20th century, pain was conceptualised "as a specific, straight-through sensory projection system" (Melzack and Katz 2006, 129). Guided by this "specificity theory", inherited from Descartes, researchers focused their efforts on localising specialised fibres and nervous pathways that would transmit to a passive pain centre in the brain the nociceptive impulses triggered by injury. "The psychological experience of pain, therefore, was virtually equated with peripheral injury" (129). This description is comparable with that of taste as expounded in the work of Bach presented above-where taste is simply the relation 
between the wine as a purely chemical object, and our gustatory and olfactive chemoreceptors, language and any cognitive work being left out.

Today however, consensual models of pain distinguish three determining aspects of pain experience: sensory-discriminative, motivational-affective and cognitiveevaluative. Far from being exclusive aspects of pain, these dimensions seem so basic as to characterise almost any conscious experience, including of course the experience of taste, and maybe especially of wine-tasting. Indeed, wine tasting is a complex cultural practice whose very existence implies more than a purely sensorydiscriminative relation to the world, appearing predisposed to motivational-affective and cognitive-evaluative determination.

But research on pain can teach us much more on perception than its fundamental multidimensionality. Indeed, the remarkable phenomenon of phantom pain (which can be felt not only by an amputee in his severed limb, but also by individuals born without a limb) has led researchers to conclude that "the brain generates the experience of the body" and that "[s]ensory inputs merely modulate that experience; they do not directly cause it" (138). This supports our conception of the experience of wine flavour as being not exclusively determined by inputs from the peripheral sensory apparatus. The experience of taste should be conceived as a complex and evolving assemblage of sensory-discriminative information, motivational-affective modulation and cognitive-evaluative appraisal executed by the central nervous system, and not as the independent quality of a physical object detected by our chemoreceptors. Summing up such a position, Melzack and Katz write:

"These views are in sharp contrast to the classical specificity theory in which the qualities of experience are presumed to be inherent in peripheral nerve fibres. Pain is not injury; the quality of pain experiences must not be confused with the physical event of breaking skin or bone. Warmth and cold are not "out there" and temperature changes occur "out there," but the qualities of experience must be generated by structures in the brain. There are no external equivalents to stinging, smarting, tickling, itch" (136).

The manner in which Melzack and Katz explain or describe pain is very useful for us here. Even though the experience of pain is usually triggered by injury, in the end it is entirely generated by the central nervous system, and does not necessarily reflect the particular interaction that originally caused it. If injury is an interaction between beings, pain is the interpretative result of this relation. Think for example how the same interaction can produce different interpretative reactions: cutting yourself while absorbed in work will not result in the same pain as mutilating yourself consciously. As there is no external equivalent to stinging or tickling, there is no external equivalent to citrusy or apple flavour. Flavours are not "out there", waiting to be tasted, but are multidimensional experiences generated by the brain, normally in response to certain stimuli arriving from the peripheral nervous system.

\section{Sommeliers, Novice Drinkers and Their Respective Umwelts}

Gustatory stimuli are the results of connections between chemoreceptive sensors and their objects, hydrophilic molecules; olfactive stimuli are the result of a connection 
between chemoreceptive sensors and their objects, volatile molecules. Clearly, if we lack certain receptors, a number of entities in the world will go by unnoticed, will not be construed as objects and will not participate in relationships tying the creature to the world. In the case of flavours, if a creature lacks a receptor that would be cued to a specific molecule, the molecule exists, but not - as a flavour-for the creature who cannot interpret it.

As biochemical signals, citrusy and apple flavours are, first and foremost, the products of one's sensory reactions to a given set of molecules. However, as the complex experiences we call flavours, they are not detected by our chemoreceptors as such, rather they result from an interaction between biochemical signals and human symbols. We will soon illustrate how experimental studies posit a link between these two biosemiotic domains.

The idea that experiential processes, including semiosis, are determined by anatomy and the functions anatomy enables, is at the heart of biosemiotics ever since it was founded by Jakob von Uexküll (and "discovered" as such by Thomas Sebeok). An important point Uexküll insisted on, and useful for us here, is his distinction between the umwelt and the surroundings, clearly explained in his 1934 Streifzüge durch die Umwelten von Tieren und Menschen. The umwelt is composed of entities that have some sort of value or meaning for a creature, objects, whereas the surroundings are composed of entities remaining at the state of things, which are ignored and go by unnoticed. Things exist, they are however meaningless. If we apply such a model to wine-tasting, we could say that novice drinkers are creatures for whom subtle tannins are meaningless entities; while for sommeliers, these tannins must be noticed, or objectified, if they want to "survive" in their professional umwelt.

Uexküll's theory of meaning entails a few points worth reminding. First, the same entity is not necessarily meaningful for all creatures, but depends on their sensors. Second, the meaning of an entity is not necessarily identical for all. Uexküll's wellknown example of the oak tree beautifully illustrates this idea (94-99): an oak tree can possibly be a number of cords of wood for the lumberjack, possibly be a burrow for a fox, possibly be a nest area for a bird, etc. The hazy and shifting frontiers of an umwelt are thus determined by the lifestyle, habits and necessities of the creature. It is therefore absurd to ask simply what the meaning of a particular entity is. As basic semiotics prescribes, meaning is an evolving relation between this entity and something or someone else. Only once the context and semiotic agent are determined, can meaning be assigned. By definition, objects never exist alone, but are always objects for an agent. There is no such thing as a taste, a texture, or a smell as such, but only a taste, a texture, or a smell for a given interpretant or effect.

Within the specific case of wine tasting, when a drinker says "this tastes of lime", he is also enouncing his cultural, practical, biological contexts. The umwelt in which wine-tasting is embedded is as natural as it is socio-cultural. Wine flavours depend on this umwelt as it is developed by tasters. So we could say that wine-tasting simultaneously needs and contributes to the development of viticulture technologies and œnological discourses.

Meaning is not limited to the mental level, but embraces all semiotic relations or developments triggered through contact with objects. In other words, and this should come as no surprise, the pragmatic principle determines meaning. A flavour is 
determined by the effects emerging from the tasting relation, by the multiple reactions it produces, even by the actions it allows the agent to perform. In the case of wine tasting, a sommelier and a novice can drink from the same glass, their experiences, effects of the complex semiotic process of tasting, will nonetheless be different.

The concept of umwelt can help us describe this phenomenon. Sommeliers and novice drinkers do not share the same umwelt. Indeed, the umwelt of a sommelier consists of "Assirtiko" and "Athiri", "tannins" and "bouquets"; then again, as Goode mentions $(2007,89)$, sommeliers differ, one may be a real expert on Australian reds, but a beginner with a German Riesling (or a Greek Assirtiko). These qualities, meaningful and perceptible for the sommeliers, are part of the ignored surroundings for the novice drinker. Therefore, sommeliers live in a more complex "olfactory semiosphere" 2 .

When a sommelier speaks of "Assirtiko" and "Athiri", "tannins" and "bouquets" to describe his experiences, he is participating in the exchange of meaning within his cultural umwelt. At this point, we will consider the properly biological distinctions to which culture relates, from which culture evolved. Not only is the umwelt of a sommelier shaped by culture, it also engages qualitative biological differences; cognitive, biological as well as social development basically underlie the sommelier's expertise. This is why semiotics and biosemiotics especially, which have set out to bridge the conventional divide between nature and culture, can be of interest.

\section{Testing Taste: Experimental Studies}

Let us now turn to a series of experimental studies revealing the interdependence of biological and cognitive development. The problem psychologists and neurologists mainly focus on when it comes to wine is the discriminatory capacity of experts versus novice drinkers. The number of scientific studies relating to wine-tasting and evaluation is impressive, especially if one considers how inconsistent the results are. Some studies (Solomon 1990, 1997) have shown that sommeliers surpass by far novices when it comes to associate and identify wines. Others (Bende and Nordin 1997; Parr et al. 2002) have found no meaningful difference between the discriminatory performances of the expert and the novice. Though results rarely concur, most researchers readily admit that sommeliers are experts of sorts endowed with a remarkably dense lexical system.

The importance of knowledge and wine-tasting has been recently supported by an oft-quoted study using functional Magnetic Resonance Imaging, "The appreciation of wine by sommeliers: a functional magnetic resonance study of sensory

\footnotetext{
${ }^{2}$ This expression is used by neurolinguist Tatiana Chernigovskaya. In her article "Cognitive struggle with sensory chaos: Semiotics of olfaction and hearing" (2004), Chernigovskaya examines the revealing case of the blind: "(b)lind musicians touring with an orchestra told me that they had vivid olfactory portraits of cities and towns, to say nothing of such portraits of other people, stores, transport, and streets. Their olfactory semiosphere is much richer than that of an average person." (67). Like the blind, it is to be expected that sommeliers, who resort constantly to sense of smell and taste, have a richer sphere of flavours.
} 
integration" (2005). The study by Alessandro Castriota-Scanderberg et al. revealed that the activation profile of seven sommeliers differed significantly from that of seven matched controls. Sommeliers and controls were given to drink various wines and neutral solutions during brain imaging. Certain areas of the brain were somewhat equally activated in all participants, namely the insular cortex (associated with limbic functions such as emotions and memory) and the orbitofrontal cortex (implied in cognitive processes such as decision-making, emotional processes such as reward, as well as sensory integration). The activation of the amygdala and hippocampus (associated with motivation and memory) was immediate with the sommeliers, and slower with the controls. The most remarkable difference however lied in the consistent stimulation of the sommelier's dorsolateral prefrontal cortex (DLPFC), implicated with the elaboration and application of high level cognitive strategies. Castriota-Scanderberg writes:

"Our finding of a significant activation of the DLPFC (BA 46) in sommeliers, but not in controls, confirms and extends previous results, suggesting that this brain region may be important in optimizing or modifying taste-related behavioral strategies involved in executive control (or alternatively, in attentional processing of taste inputs) and is modulated by the specific ability of professional sommeliers to taste wine. [...] In conclusion, our results suggest that the pattern of the brain activations is substantially different in experienced sommeliers than controls. A more refined sensitivity to combined olfactory and taste perception in sommeliers and recourse to more analytical or cognitive evaluation strategies are likely to account for this difference." (577).

What is interesting for us is the idea that levels of expertise clearly modulate brain activation, which in turn modulates gustatory and olfactive experience.

Here again, Goode appropriately formulates this phenomenon in "Wine and the Brain" (2007). He states that learned high-level cognitive processes, such as linguistic evaluation, help sommeliers to "recruit more brain areas to help with a complex task. Experienced wine tasters [pull] in new brain areas to help with the analysis of sensory stimuli." (89). Within a Peircean context, we would say that the semiotic relation between the sommelier and the wine participates in a longer-lasting chain of meanings, compared to that of a novice drinker. In other words, the sommelier's wine-tasting experience is enriched by previous sign-making having produced complex interpretants, habits and knowledge. This sign-making "opens up" various neural networks, allowing access to a higher number of features of the object, in this case the wine, making it more and more complex.

It is thus clear that knowledge, language and the processing of sensory information are co-dependant. Castriota-Scanderberg's results strengthen a thought-provoking hypothesis formulated by Gordon Shepherd, a professor of neurobiology. In "The Human Sense of Smell: Are we Better Than we Think?" (2004), Shepherd suggests that human olfaction, considered, mainly out of habit, as underdeveloped compared to other mammals such as dogs and rodents, is in fact buttressed by linguistic organisation (as well as the actual anatomy of the snout / nose and disposition of olfactory filaments). Though human beings have only 350 functional odour-related genes (as a comparison, mice have 1100) Shepherd claims that the linguistic organisation that has developed in humans, supplements amply the way humans 
process olfactive information (574-575). Neurolinguist Tatiana Chernigovskaya (2004) touches a similar idea, stating that language allows us to organise the sensory chaos we continually face, arranging and normalising our experiences. In which case, one must not underestimate the important interaction between our biological senses and language, the human animal's species-specific modelling system (Sebeok and Danesi 2000, 83-85).

It follows that one of the main differences between a sommelier and a novice concerns the expert's capacity to arrange and normalise his sensory experience through linguistic and cognitive operations, a task demanding that he focuses his attention on specific aspects of his activities. This most likely could, but does not, take place in the novice. This focusing or piloting of attention determines in part the actual conscious experience we have of this activity and can be facilitated by structured language.

An interesting case of this operation is found in another very revealing fMRI study, conducted by Fabian Grabenhorst et al. (2008). The researchers analysed the relation between cognition and gustatory experiences. Though their study is not specifically wine-related, the conclusions reached at are nonetheless relevant for us. Twelve volunteers tasted different Monosodium Glutamate and vegetable broth based products, the pleasantness and intensity of which they were asked to evaluate. During this task they read labels that did not necessarily match what they were tasting. The study showed that the labels clearly modulated the perceived taste. A revealing example: a same solution was presented under two labels, "rich and delicious flavour" and "boiled vegetable water". Not only did the "rich and delicious flavour" receive a considerably higher grade, which is not surprising, but it also generated a higher activity in the medial orbitofrontal cortex, implicated in decision-making and sensory integration. In other words, what the volunteers knew by reading the labels modified, and in some ways determined in a top-down process, what they tasted. This case reveals how gustatory experiences are complex results of simultaneous high order cognitive processes, affective or motivational dispositions, and peripheral sensory information. It is interesting to note how wine-tasting, and gastronomy in general, operate by enhancing the activation of each of these three levels, transforming the simple act of feeding into a rich semiosic operation where food and drink become complexified objects, producing complexified interpretants.

Linguistic conventions and uses surrounding wine-tasting are an important part of such an operation, and thus influence the sensational experience of sommeliers. In this regard, linguistic analysis of tasting notes is revealing such as Rosario Caballero, professor of Modern Languages, demonstrates in his paper "Manner-of-motion verbs in wine description" (2007). Tasting notes are, as Caballero observes, frequently figurative and as such they participate in the construction of the cultural umwelt of the sommelier. Caballero notes the recurring use of what he calls manner-of-motion verbs in wine notes, for example: burst, emerge, come, jump, weave, glide, creep, etc (2111). In the Sigalas Santorini 2005 one might say the green apple "emerges", whereas the lime "creeps". The use of these verbs highlights certain qualities of the wine such as intensity, persistence, and evolution as it is put in contact with air, then sipped and swallowed. By highlighting those qualities, linguistic conventions and uses guide the multidimensional interpretative process that will result in the experience of taste. 
As these studies suggest, gustatory and olfactive experiences are influenced by linguistic usage and, more generally, by cognitive-evaluative processes. Since language and knowledge are constantly evolving on the individual as well as cultural level, sensory appreciation is prone to development. It is thus highly probable that the ability of professional wine tasters to mobilize new brain areas to help with the analysis of sensory stimuli (as discussed in Castriota-Scanderberg et al. 2005, Goode 2007) is, in part, related to their mastering of linguistic and conceptual categories used within their environment. Evolution is encouraged by the necessities of a lifestyle (for professional or personal reasons) which define or modulate a specific umwelt.

\section{Conclusion}

We have seen how a relational conception of flavour helps us avoid the sterile dualistic paradigm explaining sensation in terms of objectivity or subjectivity. Jamie Goode's appropriate approach to wine-tasting describes how the work of the sommelier is in fact relational. Furthermore, the distinction between the experience of pain and peripheral injury allowed us grasp how flavours are emerging properties, produced by the convergence of sensory-discriminative, motivational-affective and cognitive-evaluative factors. Drawing from fundamental biosemiotics we then exposed how these factors vary according to the creature and its simultaneously biological and cultural umwelt. We concluded by examining a series of empirical studies consolidating the idea that sensation is informed by knowledge and language.

The notes of a wine critic are therefore transcriptions of sorts of the actual tasting event, where the sommelier uses his knowledge in order to evaluate, discriminate and transcribe the multiple responses of his central nervous system to peripheral sensorial cues. It is to be expected that the sommelier's frequent exposure to wine, to wine related-practices and knowledge eventually strengthen neural networks that do not develop in the novice. Thus the brain changes with experience and training and drinking... This in turn modulates the interpretations one makes of the world. This is why semiotics, and biosemiotics especially, can be of interest when it comes to understanding why one glass of Sigalas Santorini 2005 can produce so many experiences: from lime to lemongrass, and from apple to socializing. Cheers.

\section{References}

Allhoff, F. (Ed.) (2008). Wine and philosophy. A symposium on thinking and drinking (p. 308). Padstow: Blackwell.

Bach, K. (2007). Knowledge, wine, and taste: What good is knowledge (in enjoying wine)? In B. Smith (Ed.), Questions of taste. The philosophy of wine (pp. 21-40). New York: Oxford University Press.

Bach, K. (2008). Talk about wine? In F. Allhoff (Ed.), Wine and philosophy. A symposium on thinking and drinking (pp. 95-110). Malden, MA: Blackwell Publishing.

Bende, M., \& Nordin, S. (1997). Perceptual learning in olfaction: professional wine tasters versus controls. Physiology \& Behavior, 62, 1065-1070.

Caballero, R. (2007). Manner-of-motion verbs in wine description. Journal of Pragmatics, 39, 2095-2114.

Castriota-Scanderberg, A., Hagberg, G., Cerasa, A., Committeri, G., Galati, G., Patria, F., et al. (2005). The appreciation of wine by sommeliers: a functional magnetic resonance study of sensory integration. NeuroImage, 25, 570-578. 
Chernigovskaya, T. (2004). Cognitive struggle with sensory chaos: semiotics of olfaction and hearing. Semiotica, 150(1-4), 61-75.

Goode, J. (2007). Wine and the brain. In B. Smith (Ed.), Questions of taste. The Philosophy of wine (pp. 79-98). New York: Oxford University Press.

Grabenhorst, F., Rolls, E. T., \& Bilderbeck, A. (2008). How cognition modulates affective responses to taste and flavor: Top-down influences on the orbitofrontal and pregenual cingulated cortices. Cerebral Cortex, 18(7), 1549-1559.

Melzack, R, \& Katz, J. (2006). Pain in the 21st century: The neuromatrix and beyond. In G. Young, K. Nicholson, \& A. Kane (Eds.), Psychological knowledge in court (pp. 129-148). New York: Springer.

Parr, W., Heatherbell, D., \& White, K. G. (2002). Demystifying wine expertise: olfactory threshold, perceptual skill and semantic memory in expert and novice wine judges. Chemical Senses, 27, 747-755.

Sebeok, T., \& Danesi, M. (2000). The forms of meaning. Modelling systems theory and semiotic analysis (p. 249). Berlin: Mouton de Gruyter.

Shepherd, G. (2004). The human sense of smell: are we better than we think? PLoS Biology, 2(5), 572575.

Smith, B. (2007a). The objectivity of tastes and tasting. In B. Smith (Ed.), Questions of taste. The philosophy of wine (pp. 41-77). New York: Oxford University Press.

Smith, B. (2007b). Questions of taste. The philosophy of wine (p. 222). New York: Oxford University Press.

Solomon, G. (1990). Psychology of novice and expert wine talk. The American Journal of Psychology, 103(4), 495-517.

Solomon, G. (1997). Conceptual change and wine expertise. The Journal of Learning Sciences, 6(1), 4160.

von Uexküll, J (1956). Streifzüge durch die Umwelten von Tieren und Menschen. Bedeutungslehre (p. 181). Hamburg: Rowolt [1934]. 